\title{
Do patients' information needs decrease over the course of radiotherapy?
}

\author{
Kirsten F. L. Douma • Caro C. E. Koning • \\ Linda C. Zandbelt • Hanneke C. J. M. de Haes • \\ Ellen M. A. Smets
}

Received: 12 November 2010 / Accepted: 1 November 2011 /Published online: 13 November 2011

(C) The Author(s) 2011. This article is published with open access at Springerlink.com

\begin{abstract}
Purpose We aimed to investigate if cancer patients' information needs decrease during radiotherapy and if so, which patient, consultation and radiation oncologist characteristics are associated with a decrease in information needs over time.

Methods In this longitudinal study, patients $(n=104)$ completed a baseline questionnaire a week before the initial radiotherapy consultation, immediately following this initial consultation, and 1 week prior to the first follow-up visit, which took place on average 3-5 weeks after the initial visit. Besides information needs, measured by the Information Preference for Radiotherapy Patients scale, the questionnaire assessed patient, consultation and radiation oncologist characteristics.

Results Information needs decreased over time, but remained at a high level. Being religious, being male, having low health literacy and higher perceived involvement during the consultation were all statistically signifi-
\end{abstract}

K. F. L. Douma • H. C. J. M. de Haes • E. M. A. Smets Department of Medical Psychology, Academic Medical Center, Amsterdam, The Netherlands

C. C. E. Koning

Department of Radiation Oncology, Academic Medical Center, Amsterdam, The Netherlands

\section{C. Zandbelt}

Department of Quality and Process Innovation,

Academic Medical Center,

Amsterdam, The Netherlands

K. F. L. Douma $(\bowtie)$

Department of Medical Psychology, Academic Medical Center/

University of Amsterdam,

P.O. Box 22660, 1100 DD Amsterdam, The Netherlands

e-mail: K.F.Douma@amc.uva.nl cantly associated to a decrease in information needs on specific domains (e.g. procedures or side effects).

Conclusions Cancer patients' information needs decline between the initial consultation and the first follow-up visit, but remain high. It is therefore advised to investigate the patients' information needs at every radiotherapy visit and not rely on giving information just once. Furthermore, radiation oncologists should check if the information given at first consultation is understood and remembered. By those means, tailored information giving becomes possible.

Keywords Information needs · Radiotherapy · Cancer . Physician-patient interaction $\cdot$ Longitudinal study

\section{Introduction}

Since the 1980s attention has been drawn towards the information needs of cancer patients and their right to be fully informed. Until then, most physicians disclosed selected information only [1]. Numerous studies now show that cancer patients in general prefer to be fully informed [2].

About half of cancer patients receive radiotherapy during their treatment [3]. Radiation therapy is beneficial in the treatment of almost every solid cancer type. It is, however, difficult for patients to comprehend because it is not visible [4]. Furthermore, given the complexity and unpleasant side effects of the treatment and the importance that patients do understand procedures and follow-up advice, informing them well is essential. Information giving is likely to reduce patients' fears about treatment [5].

However, full information provision is not beneficial to all patients. Sometimes patients perceive that they are given too much information or details [6]. Quantitative studies 
report a minority of $5-36 \%$ of patients not wanting to know all details of their disease and treatment [7-11]. Denial [12, 13], difficulties in fully understanding information [13], not wanting to be involved in the medical decision-making [14, 15] or culture-determined attitudes [16, 17] may lead patients to prefer limited information. We found that among patients starting radiotherapy, a need for optimism was the most often mentioned reason to refrain from available information [18]. Furthermore, in this patient group, a lower information need was associated with being older and male, having lung or rectal cancer, more difficulty with understanding and a higher trait anxiety level [19].

Variation in information preferences may also result from the passing of time since diagnosis. It is imaginable that patients have a high information need at a first consultation; but how is this need at the follow-up visit? Does the patient need the same amount and kind of information? Studies addressing changes in information need over time showed that information needs generally remain high as patients move through different treatment stages [6, 20-22]. However, some patients prefer less information as time passes since their first diagnosis [2227]. The domains patients prefer to be informed about vary when treatment progresses [2, 28, 29]; for example, at diagnosis, individuals rank information about treatment as most important, while some months later, they want information about family risk [29].

Results from the studies so far cannot be directly extrapolated as only few of these studies specifically focused on patients receiving radiotherapy $[20,23,26$, 28] or included only specific patient groups [6, 21, 23, 27, 29]. Furthermore, the studies focusing on radiotherapy do all, except for one [28], solely involve breast cancer patients. Of the longitudinal studies performed $[6,20,26$, $28,29]$, none focused on the relative short term, e.g. differences in information needs from consultation to consultation. Previous consultations could have left the patient with specific uncertainties and expectancies. A previous contact can influence the process of information giving at a follow-up contact [30]. One could expect information needs to decrease as many radiation oncologists strongly invest in information giving during the initial consultation. Furthermore, when patients undergo radiotherapy, their questions probably decrease as they get familiar with the procedure and are able to ask questions to other team members involved in the radiotherapy (e.g. radiotherapists). However, studies so far show mixed results; patient's information needs do not or only slightly decrease over the course of radiotherapy $[20,23,26]$. Therefore, we want to investigate the hypothesis that information needs decrease over time.

To tailor information, it is important to understand why and how factors might change information needs between adjacent consultations. A study by Butow et al. among cancer patients showed that lowered information needs at follow-up consultation depended on the radiation oncologist that had seen the patient. Patients' sociodemographic or clinical characteristics were not related to a change in information needs [25].

In earlier studies, preferences for less information differed depending on patients' age [31-33], gender [6, 9, 25], level of education [31, 34], anxiety levels and intellectual ability to understand medical information [13]. However, some studies showed no significant associations between information needs and gender [35] and level of education [36-38]. Therefore, these patient characteristics need to be considered to better understand change in information needs. Time between consultations may be important too, as recall of information could be related to changes in information needs. Finally, radiation oncologist characteristics, such as gender and experience, are relevant as these are known to influence doctors' behaviour of information giving $[39,40]$ and thereby could influence the information needs between visits.

In the current prospective, longitudinal study, we therefore address two research questions: (1) do patients' information needs decrease during the course of radiotherapy and (2) if so, which patient, consultation and radiation oncologist characteristics are associated with a decrease in information need over time? With these results, we aim at gaining understanding of how patients' information needs change from visit to visit in order to be able to better tailor information giving.

\section{Materials and methods}

\section{Study sample}

Nine radiation oncologists and six trainees of the outpatient radiotherapy department of the Academic Medical Center in Amsterdam agreed to participate in the study. Their consecutive, new patients were selected. Exclusion criteria were: age $<18$ years, having undergone radiotherapy before, unable to read and write Dutch and presenting with cognitive problems or a brain tumour.

\section{Procedures}

Eligible patients were mailed a questionnaire before their first radiotherapy consultation. They were phoned some days later to invite for participation. Patients who gave informed consent were asked to complete a baseline questionnaire in the week before the initial consultation, a checklist immediately following this initial consultation and a follow-up questionnaire 1 week prior to the follow-up 
visit. The initial visit with a radiation oncologist is generally structured around the following tasks: gathering information about patients' medical history, family and work situation and current physical functioning; conduct physical examination; explain treatment plan, procedures, side effects; and making recommendations. Between initial visit and start of radiation, the patient is prepared for radiotherapy through a simulation procedure guided by a radiotherapist. The radiation period can vary from a onetime radiation to 7 weeks of radiotherapy, 5 days a week. During radiotherapy, patients commonly see the radiation oncologist once a week to follow-up on treatment and address questions. A radiotherapist is present at every radiation session. In our study, most of the follow-up visits took place, on average, 3-5 weeks after the initial visit. This was due to the time necessary for planning and preparing the radiotherapy.

The study design is shown in Fig. 1. The study was approved by the ethical committee of the Academic Medical Center.

\section{Measures}

\section{Information needs}

We developed the Information Preferences of Radiotherapy Patients Questionnaire (IPRP) [19] which specifically assesses patients' need for information from their radiation oncologist about radiotherapy. This 35-item questionnaire consists of six domains: (1) disease (five items; $\alpha=0.93$ ), (2) treatment (five items; $\alpha=0.79$ ), (3) procedures (six items; $\alpha=0.89$ ), (4) side effects (seven items; $\alpha=0.92$ ), (5) prognosis (seven items; $\alpha=0.94$ ) and (6) psychosocial aspects (four items; $\alpha=0.86$ ). For all questions, response categories on a five-point scale ranged from 'I want to know nothing about it' to 'I want to know all about it'. A higher score reflects a higher information need. The questionnaire has high reliability on the total scale ( $\alpha=$ $0.97)$ as well as subscales $(\alpha=0.84-0.94)$. Concurrent validity was found to be good as indicated by significantly positive associations with patients' general information preference, the amount of detail required and a monitoring coping style [19].

\section{Predictors of information needs}

1. Patient characteristics

(a) Sociodemographic and clinical variables

Age, gender, marital status, having children, employment status, ethnicity, native language and religion were assessed by self-report at baseline. Diagnosis and time of first diagnosis were assessed by medical record audits. Self-reported health status was assessed with one item of the EORTC-QLQ-C30 [41, 42] measuring global health.

(b) Level of health literacy and numeracy

The patients' level of understanding was assessed at baseline using (1) health literacy, i.e. the ability to perform basic reading and numerical tasks required to function in the health care environment (three items, Cronbach's $\alpha=0.63$ ) [43]; (2) numeracy, i.e. understanding of quantitative information, using four questions covering the use of proportions and percentages (Cronbach's $\alpha=0.59$ ) [44]; and (3) self-reported educational level.

(c) Level of anxiety and denial

The patients' level of anxiety and denial were assessed at baseline with extensively validated instruments: (1) the anxiety subscale of the Hospital Anxiety and Depression Scale [45]; (2) the subscale trait anxiety of the State-Trait Anxiety Inventory [46]; (3) the Fear of Cancer Scale [38]; and (4) the subscale avoidance from the Impact of Event Scale [47] assessing patient's preference for a denying coping style. These are extensively used and validated instruments.

2. Characteristics of the consultations

Time between initial and follow-up visit was assessed.

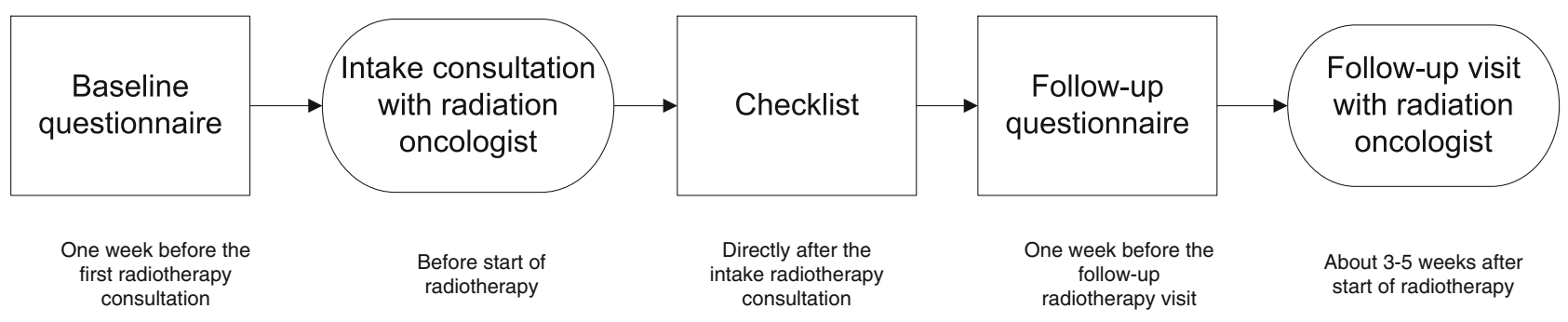

Fig. 1 Study design 
Patients' satisfaction with the initial consultation overall, with information needs met, and with the behaviour of the radiation oncologist as trying to involve them during the consultation were assessed with three questions from the PSQ [48], immediately following the initial consultation. Response categories on a $100-\mathrm{mm}$ visual analogue scale ranged from 'not satisfied at all' to 'very much satisfied' and 'not involved at all' to 'very much involved', respectively.

3. Characteristics of the consulted radiation oncologist

Prior to inclusion of patients, radiation oncologists completed a short questionnaire assessing their gender and years of experience in medical practice.

\section{Data analyses}

Descriptive statistics were used to characterise the study sample. We compared the individuals who completed both measurements with the total sample with Pearson Chisquare, Mann-Whitney and independent $t$ tests as appropriate. Reliability was determined by calculating Cronbach's $\alpha$ 's.

To assess if patients' information needs decrease during the course of radiotherapy, total subscale scores were calculated, as well as a total IPRP score (range 1-5). The number of items in the subscales of the IPRP varies; therefore, mean percentage scores were calculated in order to compare subscale scores. Responses to the IPRP appeared to be highly skewed, both on the total scale and on most subscales (5/6). The IPRP total scale was thus cubically transformed to obtain an approximately normal distribution. The IPRP subscales were too heavily skewed to be transformed. They were dichotomized, with average responses below 4 labelled as a lower information need and average responses of 4 and above indicating high information preference. Paired $t$ tests for within-subjects design (for the transformed total scale) and Wilcoxon signed-rank tests (for the subscales) were carried out to determine change in information need between baseline and follow-up.

A change in information need was also described by a medium-sized difference, a difference of a half standard deviation [49], on the total scale and the subscales of the IPRP. Whether there were differences in the pattern of changes across the domains was tested with Chi-square tests.

To determine which patient, consultation and radiation oncologist characteristics were associated with a decrease in information need over time, predictors of a decrease in information needs (versus increase and stable) were explored using bivariate logistic regression analyses for the transformed total IPRP scale and subscales separately. All analyses were carried out with SPSS version 16.0. A $p$ value of 0.05 (two sided) was considered significant.

\section{Results}

Sample characteristics

Of 293 eligible radiotherapy patients, 159 (54\%) agreed to participate. Five participants had too many missing values on the IPRP at baseline and were excluded from further analyses. Of the remaining 154 patients, 104 (68\%) also completed the IPRP at follow-up. Those who completed the IPRP on both baseline and follow-up did not differ significantly in age $(p=0.75)$, gender $(p=0.86)$ and IPRP total score at baseline $(p=0.69)$ from those who only completed the IPRP at baseline.

Table 1 shows the sociodemographic and clinical characteristics of the 104 respondents available for analyses. Mean time between initial and follow-up visit was 34 days $(\mathrm{SD}=22)$. There was an outlier with 179 days between initial and follow-up visit. She had had her initial consultation before she underwent surgery and chemotherapy and started radiotherapy only after the chemotherapy was completed.

Decrease in information need over time?

Overall, patients' information need declined significantly from initial to follow-up visit for all domains except psychosocial issues (see Table 2). More specifically, information needs of $26-37 \%$ of the patients declined (i.e. decreased more than one half standard deviation) on the different domains, while $10-24 \%$ of patients had increased information needs over time and $39-62 \%$ of patients did not change (see Table 3). Domain preferences stayed roughly the same, with the highest need for information about side effects at both baseline and follow-up (see Table 2). The pattern of change of the domain psychosocial issues differed significantly $(p<0.05)$ from the other domains, with significantly more patients who changed in their needs between consultations.

Explaining a decrease in information need over time

There were no characteristics associated with the IPRP total score (information needs in general) (data not shown).

1. Patient characteristics

(a) Sociodemographic and clinical characteristics

Being male was significantly associated with a decrease in information need about procedures $(p=$ 0.01 , exp $b=0.28,95 \% \mathrm{CI}=0.10-0.76$ ). Being religious was significantly associated with a decrease in information need about procedures $(p=0.02$, exp $b=2.83,95 \% \mathrm{CI}=1.16-6.91)$ and expected side effects $(p=0.03$, exp $b=2.87,95 \% \mathrm{CI}=1.13-7.29)$. 
Table 1 Sociodemographic characteristics of the respondents $(n=104)$

\begin{tabular}{|c|c|c|}
\hline & Mean (range) & SD \\
\hline \multirow[t]{2}{*}{ Age (in years) } & $62.6(28-86)$ & 12.6 \\
\hline & $N$ & $\%$ \\
\hline \multicolumn{3}{|l|}{ Gender } \\
\hline Male & 62 & 60 \\
\hline Female & 42 & 40 \\
\hline \multicolumn{3}{|l|}{ Marital status } \\
\hline Married/steady relation & 78 & 75 \\
\hline No partner & 25 & 24 \\
\hline \multicolumn{3}{|l|}{ Children } \\
\hline No children & 19 & 18 \\
\hline Children living at home & 17 & 16 \\
\hline Grown-up children & 67 & 64 \\
\hline \multicolumn{3}{|l|}{ Level of education $^{\mathrm{a}}$} \\
\hline Low & 74 & 71 \\
\hline High & 27 & 26 \\
\hline \multicolumn{3}{|l|}{ Employment } \\
\hline Yes & 44 & 42 \\
\hline No & 59 & 57 \\
\hline \multicolumn{3}{|l|}{ Ethnicity } \\
\hline Dutch & 99 & 95 \\
\hline Other & 4 & 4 \\
\hline \multicolumn{3}{|l|}{ Native language } \\
\hline Dutch & 97 & 93 \\
\hline Other & 6 & 6 \\
\hline \multicolumn{3}{|l|}{ Religion } \\
\hline Yes & 47 & 45 \\
\hline No & 56 & 54 \\
\hline \multicolumn{3}{|l|}{ Diagnosis } \\
\hline Breast & 19 & 18 \\
\hline Urological $^{\mathrm{b}}$ & 30 & 29 \\
\hline Gynaecological $^{\mathrm{c}}$ & 7 & 7 \\
\hline Rectum & 14 & 14 \\
\hline Esophagus & 11 & 11 \\
\hline Lung & 7 & 7 \\
\hline Gastrointestinal $^{\mathrm{d}}$ & 6 & 6 \\
\hline \multirow[t]{2}{*}{ Other ${ }^{\mathrm{e}}$} & 8 & 8 \\
\hline & Mean (range) & SD \\
\hline \multirow[t]{2}{*}{ Time between consultations (in days) } & $33.9(12-179)$ & 22.6 \\
\hline & Median, 26 & \\
\hline Duration of initial consultation (in minutes) & $46.8(17-99)$ & 16.5 \\
\hline Duration of follow-up visit (in minutes) & $10.6(3-58)$ & 7.7 \\
\hline
\end{tabular}

Due to missing data, not all percentages add to $100 \%$

${ }^{a}$ Low: no education, primary school or lower professional education. High: high school, college or university

${ }^{\mathrm{b}}$ Urological: bladder, bile duct, prostate, testis and kidney

${ }^{\mathrm{c}}$ Gynaecological: cervix and uterus

${ }^{\mathrm{d}}$ Gastrointestinal: anus, colon, stomach, pancreas

${ }^{\mathrm{e}}$ Other: skin, non-Hodgkin

lymphoma, other
No other sociodemographic and clinical characteristics were related to a decrease in information need over time (Table 4).

(b) Level of health literacy and numeracy

Lower health literacy was significantly associated with a decreased need for information about treatment $(p=0.05$, exp $b=1.75,95 \% \mathrm{CI}=1.01$ $3.05)$. Neither numeracy nor education level was related to decreased information needs.

(c) Level of anxiety and denial

Neither health-related anxiety, trait anxiety, fear of cancer nor a denying coping style were related to a decrease in information need.

2. Characteristics of the consultations

Patients' mean score on satisfaction with the initial consultation overall is $89.6(\mathrm{SD}=10.1)$, with information needs met $89.7(\mathrm{SD}=9.9)$, and with the behaviour of the radiation oncologist as trying to involve them during the consultation 82.1 $(\mathrm{SD}=15.4)$. The more individuals were satisfied with the degree to which the radiation oncologist tried to actively involve them, the more their information needs about psychosocial issues decreased ( $p=0.002$, exp $b=0.94,95 \% \mathrm{CI}=0.90-0.98)$. Time between consultations, satisfaction with the information provided and overall satisfaction were not related to a decrease in information need.

3. Characteristics of the consulted radiation oncologist

The gender of the radiation oncologist and years of experience in clinical practice were unrelated to a decrease in information need.

\section{Discussion}

Since extensive information provision may not necessarily be beneficial to all patients, we should preferably move toward patient-tailored care which takes such individual variation into account [50]. With our study, we aim at gaining understanding of how patients' information needs may change from visit to visit in order to be able to better tailor information giving. To our knowledge, this study is among the first to quantitatively investigate in the radiotherapy setting information needs over time and which characteristics are related to a possible change in needs.

The most important finding of our study is that although information needs decrease over time, they remain high for most patients. A first explanation for such a high information need might be that patients have difficulties recalling information given at the initial consultation and therefore would like to have most information repeated at the follow-up visit. Studies on recall indicate that as much 
Table 2 Information need over time $(n=104)$

\begin{tabular}{|c|c|c|c|c|c|}
\hline Information need & $n$ & Mean at baseline & Mean at follow-up & $t$ & $p$ value \\
\hline IPRP total score & 84 & $4.22(0.76)$ & $4.06(0.80)$ & 3.09 & $<0.01^{*}$ \\
\hline Information domain & & & & $z$ & \\
\hline Disease & 102 & $4.08(0.99)$ & $3.96(0.96)$ & -2.02 & $0.04 *$ \\
\hline Treatment & 97 & $4.14(0.79)$ & $3.98(0.85)$ & -2.80 & $<0.01^{*}$ \\
\hline Procedure & 101 & $4.38(0.76)$ & $4.14(0.93)$ & -3.46 & $<0.01^{*}$ \\
\hline Side effects & 100 & $4.44(0.75)$ & $4.28(0.80)$ & -2.19 & $0.03^{*}$ \\
\hline Prognosis & 99 & $4.37(0.88)$ & $4.18(1.04)$ & -2.34 & $0.02 *$ \\
\hline Psychosocial & 100 & $3.50(1.08)$ & $3.42(1.14)$ & -1.25 & 0.21 \\
\hline
\end{tabular}

A higher score reflects a higher need for information. Scores on total scale and domains range from 1-5. The table shows the non-transformed data. For the IPRP total scores, the analysis was performed using transformed scores

IPRP Information Preferences of Radiotherapy Patients Questionnaire

*Significant at $p<0.05$ level

as $50 \%$ of information may be forgotten [51-54]. This supports the recommendation by Bensing et al. [30] that researchers should not look at the communication process as an isolated event, but rather as an ongoing process. Furthermore, future studies might incorporate recall of the information given at the initial consultation as this could possibly explain the high need for information at follow-up. A second explanation for a remaining high information need among patients could be that the initial consultation left the patient with unmet information needs at the followup visit. This could have been caused by suboptimal communication by the radiation oncologist, e.g. by not explicitly checking the patients' information needs. On the other hand, patients may not have wanted to bother their doctor with their questions. This emphasises the importance of all team members involved in radiotherapy to work together in eliciting patients' information needs. A third explanation could be that seeking information is part of the patients' coping process, i.e. it is their way to gain control [55]. If so, patients will want information, regardless of the amount of information provided by the radiation oncologist and others. However, physicians' attempts to meet patients' needs in this respect will positively affect their relationship. Clearly, all these explanations are hypotheses which need further study to be confirmed.

An alternative methodological explanation for the levels of information need remaining high is the scale's wording. It is possible that we partly measured a generalised preference or trait (the individual variation in information needs) rather than a current need or state (how much the patient presently wants to know). Since a monitoring coping style is a trait, we investigated in post hoc analyses the association between information needs measured with the IPRP and the person's monitoring coping style. We found a medium association between information needs and a monitoring coping style, both at baseline and follow-up ( 0.38 and 0.45 respectively), representing a limited part of the variance (14 versus $22 \%$ ). These results suggest that we may have partly measured a generalised information preference rather than a current need. Obviously, needs

Table 3 Change of one half SD in information need between baseline and follow-up $(n=104)$

\begin{tabular}{lcllllll}
\hline Information need & \multirow{2}{*}{ Total score $(n=84)$} & $\begin{array}{l}\text { Disease } \\
N=102 \\
(\%)\end{array}$ & $\begin{array}{l}\text { Treatment } \\
N=97 \\
n(\%)\end{array}$ & $\begin{array}{l}\text { Procedure } \\
N=101 \\
n(\%)\end{array}$ & $\begin{array}{l}\text { Side effects } \\
N=100 \\
n(\%)\end{array}$ & $\begin{array}{l}\text { Prognosis } \\
N=99 \\
n(\%)\end{array}$ & $\begin{array}{l}\text { Psychosocial } \\
N=100 \\
n(\%)\end{array}$ \\
\hline Decrease $^{\mathrm{a}}$ & $n(\%)$ & $31(30)$ & $33(34)$ & $29(29)$ & $26(26)$ & $27(27)$ \\
Stable $^{\mathrm{b}}$ & $29(35)$ & $55(54)$ & $50(52)$ & $62(61)$ & $60(60)$ & $61(62)$ & $37(37)$ \\
Increase $^{\mathrm{c}}$ & $46(55)$ & $16(16)$ & $14(14)$ & $10(10)$ & $14(14)$ & $11(11)$ \\
\hline
\end{tabular}

Percentages are based on difference scores between baseline and follow-up (sum score follow-up - sum score baseline). Scores on total scale and domains range from $1-5$. Numbers do not add to 104 because of missing values

${ }^{\text {a }}$ Decrease in the sum score of the scale of one half SD or more

${ }^{b}$ Stable means that a change in the sum score of the scale is less than one half SD

${ }^{\mathrm{c}}$ Increase in the sum score of the scale of one half SD or more 
Table 4 Significant predictors of decrease in information need $(n=104)$

\begin{tabular}{|c|c|c|c|c|}
\hline & IPRP scale & $p$ & $\operatorname{Exp} b$ & $95 \% \mathrm{CI}$ for $\exp b$ \\
\hline \multicolumn{5}{|l|}{ Patient characteristics } \\
\hline \multicolumn{5}{|l|}{ Demographic and clinical variables } \\
\hline Gender & Procedures & 0.01 & 0.28 & $0.10-0.76$ \\
\hline \multirow[t]{2}{*}{ Religion: yes versus no } & Procedures & 0.02 & 2.83 & $1.16-6.91$ \\
\hline & Side effects & 0.03 & 2.87 & $1.13-7.29$ \\
\hline \multicolumn{5}{|l|}{ Level of intellectual ability } \\
\hline Health literacy & Treatment & 0.05 & 1.75 & $1.01-3.05$ \\
\hline \multicolumn{5}{|l|}{ Level of anxiety and denial } \\
\hline- & - & - & - & - \\
\hline \multicolumn{5}{|l|}{ Characteristics of the consultations } \\
\hline Patient satisfaction with involvement at intake & Psychosocial issues & $<0.01$ & 0.94 & $0.90-0.98$ \\
\hline \multicolumn{5}{|l|}{$\begin{array}{l}\text { Characteristics of the consulted } \\
\text { radiation oncologist at intake }\end{array}$} \\
\hline- & - & - & - & - \\
\hline
\end{tabular}

All shown predictors are significant at $p<0.05$ level. Bivariate logistic regression analyses in which information need is dichotomized (decrease versus stable/increase)

$C I$ confidence interval, IPRP Information Preferences of Radiotherapy Patients Questionnaire, Exp $b$ exponent of the $B$ coefficient, which is an odds ratio

are always related to personality. At the same time, we may have to reconsider the wording of the time frame when revising the IPRP eventually.

The decrease in information needs in patients with low health literacy is noteworthy; they already had lower information needs at the initial consultation [19] and now also show a greater decrease in information need over time. The association between low health literacy and decreased information needs may suggest that (at least part of) the information needs of low literate patients were met during the initial consultation. As we only globally investigated if information needs were met, this needs further study. However, this association may also mean that the communication at the initial consultation does not stimulate these individuals to get better informed at the follow-up visit, i.e. as if they have given up the effort. Low literate patients may feel ashamed when they consider their intellectual capacities as insufficient to comprehend medical information [56] or may be afraid of consuming too much of their physicians time when asking for additional explanations [13]. The few studies which examined the association between health literacy and the exchange of information during consultations suggest that low literacy patients ask fewer questions and receive less information during interactions with their physicians [57, 58]. Radiation oncologists may adapt their communication to the patient's lower information need. From the literature, it is known that physicians may perceive a patient with low knowledge as incompetent or possibly uninterested, which leads to less information giving [59]. Rather than providing less infor- mation, low literate patients probably deserve extra attention to ensure their understanding and thus support their adaptation to the treatment process. An alternative explanation for remaining high information needs among high literate patients might be that they wanted more information than what is standard given; even large amounts of information could just not have satisfied them. However, all these explanations are highly speculative and need further investigation.

We also found information needs to decrease more in men than in women. As men had lower information needs to begin with [19], their information need could have been already fulfilled for the most part at the intake consultation. Future research should take into account the amount of information that was actually given during the consultation. We find the significant association between religion and decreasing information needs harder to explain. Maybe the support of patient's religious practice may reduce the impact of the disease [60] through a cognitive process of resignation or surrender to God's will.

Interestingly, individuals who were satisfied with the degree to which the radiation oncologist tried to actively involve them in the initial consultation showed a decrease in information needs about psychosocial issues at followup. These patients possibly feel that their psychosocial (information) needs are met by the radiation oncologist and therefore have less psychosocial information needs at follow-up. This finding may be of clinical importance because early investment of the radiation oncologist in psychosocial topics, such as contact with fellow-sufferers, 
other sources for psychosocial support and financial consequences of the disease, could thus satisfy the need for additional psychosocial information.

Some limitations of this study should be noted. Overall, individuals had high scores at the Information Preferences of Radiotherapy Patients Questionnaire at baseline. So, a ceiling effect was present, making it impossible for most individuals to score higher at follow-up. Moreover, the ceiling effects lead to low variance in the data. As a consequence, it is more difficult to find significant associations. On the other hand, we performed several separate logistic regression analyses which could have led to a multiple testing bias leading to an increased chance of finding significant results. Second, in our study, we asked about information needs in relation to the consultation with the radiation oncologist. However, these information needs in part could have been met through other sources like internet, family or other health professionals. Third, the overall response rate was relatively low, which is most likely due to the fact that patients just received their cancer diagnosis and did not have the attention or energy to fill out an extensive questionnaire. Furthermore, this was part of a larger study, in which consultations with the radiation oncologist were videotaped. Some patients did not want that and therefore did not take part in the study.

In summary, this study showed that information needs decrease over time. However, they remain at a high level, and for a majority of patients, their information needs did not change. Being male, being religious, having low health literacy and satisfaction with the degree of involvement during the consultation were all associated to a decrease in some, but certainly not all domains of information needs. Overall, there were no clear outstanding characteristics that explain a decrease in information need. Although we thoroughly investigated a variety of factors which are assumed to be associated with changes in information needs over time, we are still not able to fully explain patterns in such needs. As a consequence, radiation oncologists cannot assume that at the follow-up visit, the same type of patients, for example older and male patients have low information needs as compared to the initial consultation.

Future studies might use a qualitative approach to gain more insight in how information needs develop from visit to visit. Also, in view of the fact that oncology care involves many health professionals' attention should be paid to the role of the whole team on informing the patient. In addition, future studies should measure in more detail if information needs are met.

Currently, radiation oncologists invest much effort in information giving at the initial consultation. Our results suggest that it is also necessary to shortly explore the patients' information needs at every visit and not rely on giving information once. Patients are known to be less anxious when information is spread out [61]. Furthermore, radiation oncologists should check if the information given at first consultation is well understood and remembered. By those means, tailored information giving becomes possible.

Acknowledgements This study was supported by the Dutch Cancer Foundation (grant UVA 2005-3199). We are grateful to all patients and radiation oncologists who participated in this study.

Conflicts of interest The authors have no conflict of interest to be reported.

Open Access This article is distributed under the terms of the Creative Commons Attribution Noncommercial License which permits any noncommercial use, distribution, and reproduction in any medium, provided the original author(s) and source are credited.

\section{References}

1. Holland JC (2002) History of psycho-oncology: overcoming attitudinal and conceptual barriers. Psychosom Med 64:206-221

2. Rutten LJ, Arora NK, Bakos AD, Aziz N, Rowland J (2005) Information needs and sources of information among cancer patients: a systematic review of research (1980-2003). Patient Educ Couns 57:250-261

3. van Daal WA, Bos MA (1997) Infrastructure for radiotherapy in The Netherlands: development from 1970 to 2010. Int J Radiat Oncol Biol Phys 37:411-415

4. Schafer C, Herbst M (2003) Ethical aspects of patient information in radiation oncology. An introduction and a review of the literature. Strahlenther Onkol 179:431-440

5. Stewart MA (1995) Effective physician-patient communication and health outcomes: a review. CMAJ 152:1423-1433

6. Friis LS, Elverdam B, Schmidt KG (2003) The patient's perspective: a qualitative study of acute myeloid leukaemia patients' need for information and their information-seeking behaviour. Support Care Cancer 11:162-170

7. Blanchard CG, Labrecque MS, Ruckdeschel JC, Blanchard EB (1988) Information and decision-making preferences of hospitalized adult cancer patients. Soc Sci Med 27:1139-1145

8. Fallowfield L, Ford S, Lewis S (1995) No news is not good news: information preferences of patients with cancer. Psychooncology 4:197-202

9. Jenkins V, Fallowfield L, Saul J (2001) Information needs of patients with cancer: results from a large study in UK cancer centres. Br J Cancer 84:48-51

10. Lagarde SM, Franssen SJ, van Werven JR, Smets EM, Tran TC, Tilanus HW, Plukker JT, de Haes JC, van Lanschot JJ (2008) Patient preferences for the disclosure of prognosis after esophagectomy for cancer with curative intent. Ann Surg Oncol 15:3289-3298

11. Ong LM, Visser MR, van Zuuren FJ, Rietbroek RC, Lammes FB, de Haes JC (1999) Cancer patients' coping styles and doctorpatient communication. Psychooncology 8:155-166

12. Davey HM, Butow PN, Armstrong BK (2003) Cancer patients' preferences for written prognostic information provided outside the clinical context. Br J Cancer 89:1450-1456

13. Leydon GM, Boulton M, Moynihan C, Jones A, Mossman J, Boudioni M, McPherson K (2000) Cancer patients' information needs and information seeking behaviour: in depth interview study. BMJ 320:909-913 
14. Degner LF, Kristjanson LJ, Bowman D, Sloan JA, Carriere KC, O'Neil J, Bilodeau B, Watson P, Mueller B (1997) Information needs and decisional preferences in women with breast cancer. JAMA 277:1485-1492

15. Hack TF, Degner LF, Dyck DG (1994) Relationship between preferences for decisional control and illness information among women with breast cancer: a quantitative and qualitative analysis. Soc Sci Med 39:279-289

16. Blackhall LJ, Murphy ST, Frank G, Michel V, Azen S (1995) Ethnicity and attitudes toward patient autonomy. JAMA 274:820-825

17. Bruera E, Neumann CM, Mazzocato C, Stiefel F, Sala R (2000) Attitudes and beliefs of palliative care physicians regarding communication with terminally ill cancer patients. Palliat Med $14: 287-298$

18. ter Hoeven C, Zandbelt LC, Franssen SJ, de Haes JCJM, Oort F, Geijssen D, Koning CCE, Smets EMA (2010) Measuring cancer patients' reasons for their information preference: construction of the considerations concerning cancer information (CCCI) questionnaire. Psychooncology. doi:10.1002/pon.1841

19. Zeguers M, De Haes HC, Zandbelt LC, Ter Hoeven CL, Franssen SJ, Geijsen DD, Koning CC, Smets EM (2010) The information needs of new radiotherapy patients: how to measure? Do they want to know everything? And if not, why? Int J Radiat Oncol Biol Phys. doi:10.1016/j.ijrobp.2010.09.032

20. Harrison DE, Galloway S, Graydon JE, Palmer-Wickham S, Rich-van der Bij L (1999) Information needs and preference for information of women with breast cancer over a first course of radiation therapy. Patient Educ Couns 38:217-225

21. Browall M, Carlsson M, Horvath GG (2004) Information needs of women with recently diagnosed ovarian cancer - a longitudinal study. Eur J Oncol Nurs 8:200-207

22. Mistry A, Wilson S, Priestman T, Damery S, Haque M (2010) How do the information needs of cancer patients differ at different stages of the cancer journey? A cross-sectional survey. JRSM Short Rep 1(4):30

23. Halkett GK, Kristjanson LJ (2007) Validity and reliability testing of two instruments to measure breast cancer patients' concerns and information needs relating to radiation therapy. Radiat Oncol 2:43

24. Iconomou G, Viha A, Koutras A, Vagenakis AG, Kalofonos HP (2002) Information needs and awareness of diagnosis in patients with cancer receiving chemotherapy: a report from Greece. Palliat Med 16:315-321

25. Butow PN, Maclean M, Dunn SM, Tattersall MH, Boyer MJ (1997) The dynamics of change: cancer patients' preferences for information, involvement and support. Ann Oncol 8:857-863

26. Halkett GK, Kristjanson LJ, Lobb E, O'Driscoll C, Taylor M, Spry N (2009) Meeting breast cancer patients' information needs during radiotherapy: what can we do to improve the information and support that is currently provided? Eur J Cancer Care (Engl) 19(4):538-547

27. Mesters I, van den Borne B, De Boer M, Pruyn J (2001) Measuring information needs among cancer patients. Patient Educ Couns 43:253-262

28. Dodd MJ, Ahmed N (1987) Preference for type of information in cancer patients receiving radiation therapy. Cancer Nurs 10:244-251

29. Luker KA, Beaver K, Leinster SJ, Owens RG (1996) Information needs and sources of information for women with breast cancer: a follow-up study. J Adv Nurs 23:487-495

30. Bensing J, van Dulmen S, Tates K (2003) Communication in context: new directions in communication research. Patient Educ Couns 50:27-32

31. Cassileth BR, Zupkis RV, Sutton-Smith K, March V (1980) Information and participation preferences among cancer patients. Ann Intern Med 92:832-836

32. Dale J, Jatsch W, Hughes N, Pearce A, Meystre C (2004) Information needs and prostate cancer: the development of a systematic means of identification. BJU Int 94:63-69
33. de Bock GH, Bonnema J, Zwaan RE, van de Velde CJ, Kievit J, Stiggelbout AM (2004) Patient's needs and preferences in routine follow-up after treatment for breast cancer. Br J Cancer 90:1144-1150

34. Cassileth BR, Temoshok L, Frederick BE et al (1988) Patient and physician delay in melanoma diagnosis. J Am Acad Dermatol 18:591-598

35. Meredith C, Symonds P, Webster L, Lamont D, Pyper E, Gillis CR, Fallowfield L (1996) Information needs of cancer patients in west Scotland: cross sectional survey of patients' views. BMJ 313:724-726

36. Buzaglo JS, Millard JL, Ridgway CG, Ross EA, Antaramian SP, Miller SM, Meropol NJ (2007) An internet method to assess cancer patient information needs and enhance doctor-patient communication: a pilot study. J Cancer Educ 22:233-240

37. Galloway S, Rebeyka D, Saxe-Braithwaite M, Bubela N, McKibbon A (1997) Discharge information needs and symptom distress after abdominal aortic surgery. Can J Cardiovasc Nurs 8:9-15

38. Kaplowitz SA, Campo S, Chiu WT (2002) Cancer patients' desires for communication of prognosis information. Health Commun 14:221-241

39. Street RLJ (2002) Gender differences in health care providerpatient communication: are they due to style, stereotypes, or accommodation? Patient Educ Couns 48:201-206

40. Street RL Jr, Gordon H, Haidet P (2007) Physicians' communication and perceptions of patients: is it how they look, how they talk, or is it just the doctor? Soc Sci Med 65:586-598

41. Aaronson NK, Visser-Pol E, Leenhouts GH et al (1996) Telephonebased nursing intervention improves the effectiveness of the informed consent process in cancer clinical trials. J Clin Oncol 14:984-996

42. Sprangers MA, Cull A, Bjordal K, Groenvold M, Aaronson NK (1993) The European Organization for Research and Treatment of Cancer. Approach to quality of life assessment: guidelines for developing questionnaire modules. EORTC Study Group on Quality of Life. Qual Life Res 2:287-295

43. Chew LD, Bradley KA, Boyko EJ (2004) Brief questions to identify patients with inadequate health literacy. Fam Med 36:588-594

44. Schwartz LM, Woloshin S, Black WC, Welch HG (1997) The role of numeracy in understanding the benefit of screening mammography. Ann Intern Med 127:966-972

45. Zigmond AS, Snaith RP (1983) The hospital anxiety and depression scale. Acta Psychiatr Scand 67:361-370

46. Spielberger CD (1983) Manual for the State-Trait Anxiety Inventory STAI (from Y)

47. Horowitz M, Wilner N, Alvarez W (1979) Impact of event scale: a measure of subjective stress. Psychosom Med 41:209-218

48. Zandbelt LC, Smets EM, Oort FJ, Godfried MH, de Haes JC (2004) Satisfaction with the outpatient encounter. J Gen Intern Med 19:1088-1095

49. Sloan JA (2005) Assessing the minimally clinically significant difference: scientific considerations, challenges and solutions. COPD 2:57-62

50. Sepucha K, Ozanne EM (2010) How to define and measure concordance between patients' preferences and medical treatments: a systematic review of approaches and recommendations for standardization. Patient Educ Couns 78:12-23

51. Brown RF, Butow PN, Dunn SM, Tattersall MH (2001) Promoting patient participation and shortening cancer consultations: a randomised trial. Br J Cancer 85:1273-1279

52. Graham P (2003) Type of consent does not influence patient recall of serious potential radiation toxicity of adjuvant breast radiotherapy. Australas Radiol 47:416-421

53. Jansen J, Butow PN, van Weert JC, van Dulmen S, Devine RJ, Heeren TJ, Bensing JM, Tattersall MH (2008) Does age really matter? Recall of information presented to newly referred patients with cancer. J Clin Oncol 26:5450-5457

54. Leighl N, Gattellari M, Butow P, Brown R, Tattersall MH (2001) Discussing adjuvant cancer therapy. J Clin Oncol 19:1768-1778 
55. Taylor SE (1983) Adjustment to threatening events. A theory of cognitive adaptation. Am Psychol 38:1161-1173

56. Wolf MS, Williams MV, Parker RM, Parikh NS, Nowlan AW, Baker DW (2007) Patients' shame and attitudes toward discussing the results of literacy screening. J Health Commun 12:721-732

57. Ishikawa H, Yano E, Fujimori S, Kinoshita M, Yamanouchi T, Yoshikawa M, Yamazaki Y, Teramoto T (2009) Patient health literacy and patient-physician information exchange during a visit. Fam Pract 26:517-523

58. Katz MG, Jacobson TA, Veledar E, Kripalani S (2007) Patient literacy and question-asking behavior during the medical encounter: a mixed-methods analysis. J Gen Intern Med 22:782-786
59. Hummelinck A, Pollock K (2006) Parents' information needs about the treatment of their chronically ill child: a qualitative study. Patient Educ Couns 62:228-234

60. Chen SC, Yu WP, Chu TL, Hung HC, Tsai MC, Liao CT (2010) Prevalence and correlates of supportive care needs in oral cancer patients with and without anxiety during the diagnostic period. Cancer Nurs 33:280-289

61. D' haese S, Vinh-Hung V, Bijdekerke P, Spinnoy M, De BM, Lochie N, De RP, Storme G (2000) The effect of timing of the provision of information on anxiety and satisfaction of cancer patients receiving radiotherapy. J Cancer Educ 15:223227 